\title{
HELICOBACTER PYLORI PREVALENCE IN CHILDREN INFLUENCED BY NON-SPECIFIC ANTIBIOTIC TREATMENTS
}

\author{
Antje Hoffmann ${ }^{1}$, Peter Krumbiegel ${ }^{2}$, Thomas Richter ${ }^{3}$, Matthias Richter ${ }^{2}$, Stefan Röder ${ }^{2}$, Ulrike Rolle-Kampczyk ${ }^{2}$, \\ Olf Herbarth ${ }^{1}$ \\ ${ }^{1}$ Institute of Environmental Medicine and Hygiene, Faculty of Medicine, University of Leipzig, Leipzig, Germany \\ ${ }^{2}$ Helmholtz-Centre for Environmental Research, Leipzig, Germany \\ ${ }^{3}$ Municipal Children's Hospital "St. Georg", Leipzig, Germany
}

\section{SUMMARY}

Objective: Helicobacter pylori (H.p.) infections play a very important role in the development of ulcerations and malignancies of the gastrointestinal tract. It is assumed that the primary infection occurs during childhood, depending on numerous environmental factors among them hygiene and social status. Our aim was to determine whether treatment with antibiotics affects the persistence of H.p. infection.

Methods: In 2006, we conducted an epidemiological study among all grade 8 students in the city of Leipzig (mean age 14.6 years). To determine the prevalence of H.p. infection, a voluntary H.p. test $\left({ }^{13} \mathrm{C}\right.$-urea breath test) was performed in all participants.

Results: The H.p. prevalence was 6.3\% ( $N=1,598)$. A significant difference was found between those students who had been treated with an antibiotic at least once prior to the test and those who had never received any antibiotics ( $4.0 \%$ and $11.1 \%$, respectively, $p<0.001)$. H.p. prevalence decreased with increasing numbers of antibiotic treatments.

Conclusion: In adolescence, treatment with "non-H.p. specific" antibiotics appears to significantly affect H.p. prevalence. Moreover, the actual persistence of H.p. in "chronic persistent" H.p. infections appears to fluctuate at least in younger years. Thus, any "non-H.p. specific" antibiotic treatment should be considered in the diagnosis and treatment of H.p. infections and should be taken into account as an important confounder in future epidemiological studies.

Key words: Helicobacter pylori infection, adolescents, antibiotics

Address for correspondence: $\mathrm{O}$. Herbarth, Institute of Environmental Medicine and Hygiene, Faculty of Medicine, University of Leipzig, Liebigstr. 27, 04103 Leipzig, Germany. E-mail: olf.herbarth@medizin.uni-leipzig.de

\section{INTRODUCTION}

Helicobacter pylori (H.p.) infection is an important cause of ulcerations of the stomach and duodenum as well as gastric malignancies and MALT-lymphoma (1). As one of the most prevalent chronic infections with more than $50 \%$ of the world population being infected (2), H.p. is believed to be of immense epidemiological importance. Population based prevalences of over $80 \%$ have been reported from developing countries, whereas in industrialized nations substantially lower prevalences of around $40 \%$ have been found $(1,3)$. These differences are thought to be due to a number of environmental factors. Besides different infectious pathways and better hygienic and social conditions in industrialized nations (4), the increasing use of antibiotics in the treatment of bacterial infections is seen as an additional factor (5-7). Thus, antibiotic treatments should be considered as a confounding factor in prevalence studies. However, study results are not so clear-cut. Furthermore, comprehensive epidemiologic cohort studies of children and adolescents are still missing. To our knowledge, this is the first study that focuses on the effect of nonH.p. specific antibiotic treatment on H.p. colonization in children.

Up to now, data regarding the effect of antibiotic treatment on H.p. infection has only been available in the form of studies comparing the effectiveness of different eradication strategies.
The assumption is that the infection occurs mainly during childhood (8-10) and persists throughout the life $(11,12)$. This is why epidemiologic studies during childhood and adolescence would be of clinical interest in order to detect and comprehend the factors which determine the persistence of H.p. infection. In this study, H.p. prevalence among grade 8 students in Leipzig was investigated in relation to the number of antibiotic treatments the students had received prior to the test.

\section{MATERIALS AND METHODS}

\section{Study Population and Clinical Procedures}

The investigation was carried out among grade 8 students during the spring and summer of 2006 in several public schools in Leipzig. It was the second follow-up of the large environmental epidemiologic “LISS” study (the Leipzig Study of Respiratory Disease, Allergies and Infections in School Starters) which started in 1998 among school starters who were followed up for the first time in 2000 when they reached the second grade $(13,14)$.

The study included a comprehensive questionnaire inquiry and testing of H.p. status, using the ${ }^{13} \mathrm{C}$-urea breath test. Participation was on a voluntary basis. 
To assess the effect of antibiotic treatments, the questionnaire included items about previous antibiotic treatments (prescribed antibacterial treatment against common infectious diseases during childhood) and their frequency.

From 2,994 grade 8 students of 50 schools in Leipzig, 2,133 students agreed to participate in the study. 1,992 took the breath test and 2,046 handed in a parent-completed questionnaire. The main parameters of the remaining population (mean age 14.6 years) are shown in Table 1.

The ${ }^{13} \mathrm{C}$-urea breath test was chosen because it is a non-invasive test with specificity and sensitivity of more than 95\% (15). Two exhalation breath samples were taken, one prior to and one 30 minutes after the administration of $40 \mathrm{ml}$ orange juice containing $75 \mathrm{mg}$ of ${ }^{13} \mathrm{C}$-marked urea $\left(99.3\right.$ atom $\%{ }^{13} \mathrm{C}$; chemical purity according to U.S. Pharmacopeia assay: $99.8 \%$; Chemotrade Leipzig). The test is based on the endogenous urease activity of $H$.p. bacteria. In infected study participants, bacterial urease in the stomach splits the ${ }^{13} \mathrm{C}$-marked urea and the labelled carbon isotope is then incorporated into ${ }^{13} \mathrm{CO}_{2}$, which can be detected in exhalation breath samples (measured by a 13C isotope analyzer, FANci; Dr. Fischer Analysen, Leipzig. Germany).

\section{Laboratory Procedure}

The quantity of the exhaled isotope was measured using a ${ }^{13} \mathrm{C}$ analyzer appropriate for routine use. The difference between the $\delta$-values, before and after application of the test substance, was used to determine the so-called delta-over-baseline-value (DOB value). In this study, the DOB cut-off point for H.p. infection was equal to $5 \%$ in accordance to the previous campaigns of the LISS study.

\section{Statistical Analysis}

The statistical analyses were performed using STATISTICA for Windows (Software System for Data Analyses) Version 7.1. To test the statistically significant differences of two nominally distributed factors, the $\chi^{2}$-test (chi-square-test) was used.

All study participants who had received any antibiotic treatment within four weeks prior to H.p. testing were excluded from the analysis.

The multivariate logistic regression analysis was applied to correct for various confounders known to influence the H.p. prevalence, such as crowding, SES (socio-economic status) and nationality (German vs. immigrants). The selection of confounders or factors of influence besides antibiotic treatment were based on the results of previous investigations $(14,22)$.

Only models with statistical sufficient sample size could be calculated. Significance levels for all statistical tests were set at $\alpha=5 \%$, i.e., statistical significance was defined as $p \leq 0.05$.

Crowding: "Crowding” describes the density of persons per apartment expressed as person per square meter. The risk of infection increases with increasing number of persons per square meter of living room. The participants were assigned to one of two strata. The distinguishing feature was whether the participants had more living room per person than the $25 \%$ quantil (lower quartile) $(=1)$ or not $(=0)$.

SES: To classify SES (socio-economic status) of study participants, a special "SES-score" was used that had resulted from a baby cohort study (16) investigating lifestyle factors in Leipzig. That assessment pointed to three component scores varying from zero to three, based on information about the following inquiries: family status - parents living in relationship $(=1)$ versus single parent $(=0)$; financial problems due to unemployment - at least one parent working $(=1)$ versus both parents unemployed $(=0)$; and the parents' educational level - at least one parent with a university degree (including college degree) $(=1)$ versus no higher educational level $(=0)$. The sum results in the final SES $($ minimum $=0$ and maximum $=3$ ). Zero points characterize the lowest and three the highest level. Table 1 shows the distribution of considered population in the 4 SES classes.

Nationality: Within the German population (=1) a significant lower prevalence was observed compared with the foreign population $(=0)(22)$. This is why we decided to make a distinction between both groups.

\section{RESULTS}

100 students tested positive for $H$.p. using the ${ }^{13} \mathrm{C}$-urea breath test. H.p infection prevalence among the 1,598 students amounted to $6.2 \%$ (53\% of female and $47 \%$ of male students), with no significant sex difference in the distribution $(p=0.846)$ and no significant difference between the H.p. infection prevalence (Table 1, $\mathrm{p}=0.918$ ).

Out of 1,905 schoolchildren who completed questionnaires and were tested for H.p. only 1,690 questionnaires were correctly filled in. 92 students were excluded because they had received an antibiotic treatment during 4 weeks before testing. Because the participating schools were distributed all over the city, we assume that a potential bias in respect of non responders cannot play a decisive role.

All statements about antibiotic treatment within the questionnaires were correlated with H.p. prevalence based on measurements for each student. All adolescents were included if the parents could remember that their children had ever been treated with antibiotics more than 4 weeks before testing, regardless of the reason for such a treatment. All adolescents with antibiotic therapy during the last 4 weeks or at present were excluded. The results showed that students, who had been treated in the past at least once with antibiotics, were significantly less likely to be colonized by H.p. This assessment only includes students who received nonH.p. specific antibiotic treatment, in total 1,084 children. Table 2 shows the effect of antibiotic treatment on the H.p. colonization.

Since antibiotic use and nationality may be of some importance (higher H.p. prevalence and lower antibiotic use in foreigners) we analyzed the effect of antibiotic use within the group of foreigners separately. In the subgroup of foreigners, H.p. prevalence in those treated with antibiotics and those not treated was $12.3 \%(\mathrm{n}=81)$ and $24.6 \%(n=61)$, respectively.

Moreover, a clear decrease in the prevalence of H.p. infection was observed in relation to the number of previous antibiotic treatments (Table 2). The variations are shown in Fig. 1.

The associations between H.p. colonization and antibiotic treatment were investigated using logistic regression. Since other investigations have shown an influence of age, nationality, crowding, and socio-economic factors, these confounders were included (Tables 3 and 4). 
Table 1. Demographics and H.p. prevalence of the study population

\begin{tabular}{|c|c|c|c|c|}
\hline & & & $\mathrm{N}$ & $\%$ \\
\hline \multicolumn{2}{|c|}{ Participating students } & & 2,133 & 100 \\
\hline \multicolumn{2}{|c|}{ Questionnaires completed } & & 2,046 & 95.2 \\
\hline \multicolumn{2}{|c|}{${ }^{13} \mathrm{C}$-urea breath test } & & 1,992 & 93.4 \\
\hline \multicolumn{2}{|c|}{ Students with questionnaire and test } & & 1,905 & 89.3 \\
\hline \multicolumn{2}{|c|}{$\begin{array}{l}\text { Students who performed the breath test and completed all questionnaire items } \\
\text { relevant to this study a) }\end{array}$} & & 1,690 & 79.2 \\
\hline \multicolumn{2}{|c|}{$\begin{array}{l}\text { Remaining cohort without } 92 \text { students with antibiotic treatment during } 4 \text { weeks } \\
\text { before testing }\end{array}$} & & 1,598 & 74.9 \\
\hline \multicolumn{5}{|c|}{ Characteristics of remaining cohort (related to $N=1,598$ ) } \\
\hline \multicolumn{2}{|c|}{ Mean age (years) \pm SD (standard deviation) } & $14.6 \pm 0.7$ & & \\
\hline \multicolumn{2}{|l|}{ Girls (n) } & & 816 & 51.1 \\
\hline \multicolumn{2}{|l|}{ Boys (n) } & & 782 & 48.9 \\
\hline \multicolumn{2}{|c|}{ H.p. positive students } & & 100 & 6.3 \\
\hline \multicolumn{2}{|c|}{ H.p. positive girls/boys } & & $53 / 47$ & $6.5 / 6.0$ \\
\hline \multirow{2}{*}{\multicolumn{2}{|c|}{ Non-specific antibiotic treatment }} & total & 1,084 & 67.8 \\
\hline & & several times & 837 & 52.4 \\
\hline \multicolumn{5}{|c|}{ Additional considered variables } \\
\hline \multirow{2}{*}{ Nationality } & Foreigner & & 142 & 8.9 \\
\hline & German & & 1,456 & 91.1 \\
\hline \multicolumn{2}{|c|}{ Crowding ( $<20 \mathrm{~m}^{2}$ per person and apartment) } & & 384 & 24.0 \\
\hline \multirow{4}{*}{ SES } & 0 & & 111 & 6.9 \\
\hline & 1 & & 296 & 18.5 \\
\hline & 2 & & 669 & 41.9 \\
\hline & 3 & & 522 & 32.7 \\
\hline
\end{tabular}

a)215 parents did not remember if their children had received antibiotic treatment during their lifetime. All of the following statistics are based on the dataset of remaining 1,598 students.

Table 2. Antibiotic treatment before examination and H.p. prevalence

\begin{tabular}{|l|l|c|c|}
\hline & & $\begin{array}{c}\text { H.p. } \\
\text { prevalence }\end{array}$ & n/N \\
\hline \multirow{2}{*}{$\begin{array}{l}\text { Non-specific antibiotic } \\
\text { treatment }\end{array}$} & no & 11.1 & $57 / 514$ \\
\cline { 2 - 4 } & yes & 4.0 & $43 / 1,084$ \\
\hline \multirow{2}{*}{$\begin{array}{l}\text { Frequency of antibiotic } \\
\text { treatment }\end{array}$} & once & 5.3 & $13 / 247$ \\
\cline { 2 - 4 } & several times & 3.6 & $30 / 837$ \\
\hline \multirow{2}{*}{$\begin{array}{l}\text { Date of antibiotic } \\
\text { treatment }\end{array}$} & $\begin{array}{l}\text { during the last } \\
\text { 4 weeks }\end{array}$ & 5.4 & $5 / 92$ \\
\cline { 2 - 4 } & $\begin{array}{l}\text { during the last } \\
6 \text { month }\end{array}$ & 5.2 & $10 / 191$ \\
\cline { 2 - 4 } & before 6 month & 3.7 & $33 / 893$ \\
\hline
\end{tabular}

b) Only for illustration, not included in the final cohort.

The protective effect of the non-H.p. specific antibiotic treatments and their frequency on H.p. infection was also confirmed in the multivariate, logistic regression analysis considering confounders - nationality, crowding, SES, and age (Table 3).

All 3 influencing parameters (AB antibiotic therapy - yes/no, frequency, date of examination as defined in Fig. 1) were considered in different models. All models were highly significant with $\mathrm{p}<0.00001$.

All confounders are shown in Tables 3 and 4.
Using "frequency" or "date of antibiotic treatment” separately in different models, the model parameters were changed only marginally. Importantly, no changes of the significances were observed (Table 3).

If the parameters "frequency" and "date of antibiotic treatment" were analyzed (Table 4), only the effect of frequency of antibiotic treatment remained significant.

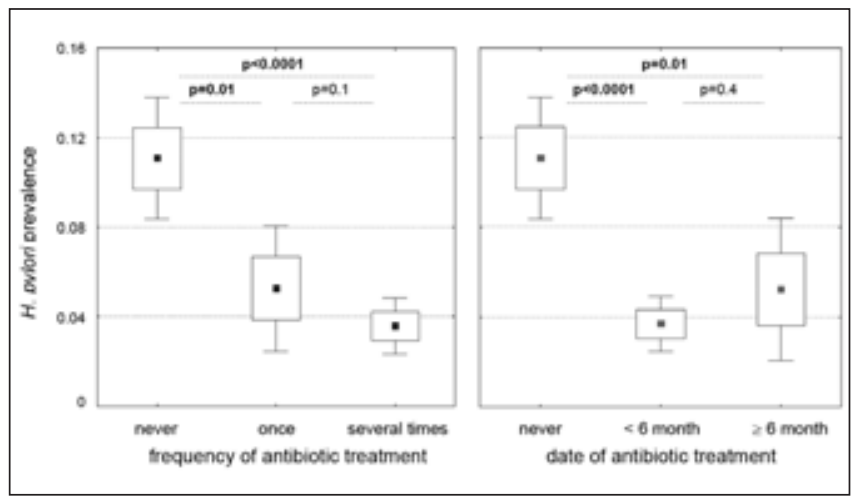

Fig. 1. Association between the prevalence of H. pylori colonization (\%/100) and frequency of non-specific antibiotic treatment (left); and date of antibiotic treatment in the past (right) related to the time point of $\mathrm{H}$. pylori investigation (arithmetic mean (匹), standard error (box) and limits of confidence interval of mean with $p=0.05$ are shown). 
Table 3. Odds Ratios (OR), 95\% Cl and p for the association between use of antibiotics (AB) and the H.p. status adjusted for nationality, crowding and SES (socio-economic status) calculated separately for each $A B$ characteristics (AB yes/no, $A B$ frequency, $A B$ date)

\begin{tabular}{|c|c|c|c|c|c|c|c|c|c|}
\hline \multirow[t]{2}{*}{ Parameter } & \multicolumn{9}{|c|}{ H. pylori status ( $1=$ infected, $0=$ not infected) } \\
\hline & \multicolumn{3}{|c|}{ Model 1} & \multicolumn{3}{|c|}{ Model 2} & \multicolumn{3}{|c|}{ Model 3} \\
\hline \multirow[t]{2}{*}{ Factor of influence } & \multicolumn{3}{|c|}{ AB yes/no } & \multicolumn{3}{|c|}{$A B$ frequency } & \multicolumn{3}{|c|}{$A B$ date } \\
\hline & OR & $95 \% \mathrm{Cl}$ & $\mathrm{p}$ & OR & $95 \% \mathrm{Cl}$ & $\mathrm{p}$ & OR & $95 \% \mathrm{Cl}$ & $\mathrm{p}$ \\
\hline Factor of influence & 0.39 & $0.25-0.59$ & $<0.001$ & 0.35 & $0.22-0.56$ & $<0.001$ & 0.28 & $0.14-0.56$ & $<0.001$ \\
\hline \multicolumn{10}{|l|}{ Adjusted for } \\
\hline Nationality & 0.30 & $0.18-0.49$ & $<0.001$ & 0.29 & $0.18-0.49$ & $<0.001$ & 0.29 & $0.18-0.48$ & $<0.0001$ \\
\hline Crowding & 1.32 & $0.84-2.07$ & 0.22 & 1.31 & $0.83-2.05$ & 0.24 & 1.36 & $0.87-2.13$ & 0.18 \\
\hline SES & 0.45 & $0.23-0.87$ & 0.02 & 0.45 & $0.23-0.89$ & 0.02 & 0.42 & $0.22-0.82$ & 0.01 \\
\hline
\end{tabular}

All models are significant with $p<0.00001$; ranges for Odds Ratios (described in the chapter "Statistical Analysis") are shown for AB frequency, AB date and SES; significant variables in bold.

Table 4. Odds Ratios (OR), $95 \% \mathrm{Cl}$ and $\mathrm{p}$ for the association between use of antibiotics (AB) and the H.p. status adjusted for nationality, crowding, and SES (socio-economic status) calculated for $A B$ frequency and $A B$ date in one model

\begin{tabular}{|c|c|c|c|}
\hline \multirow[t]{2}{*}{ Parameter } & \multicolumn{3}{|c|}{ H. pylori status ( $1=$ infected, $0=$ not infected) } \\
\hline & \multicolumn{3}{|c|}{ Model 4} \\
\hline \multirow[t]{2}{*}{ Factors of influence } & \multicolumn{3}{|c|}{$A B$ frequency and $A B$ date } \\
\hline & OR & $95 \% \mathrm{Cl}$ & $\mathrm{p}$ \\
\hline \multicolumn{4}{|l|}{ Factors of influence } \\
\hline$A B$ frequency & 0.33 & $0.14-0.77$ & 0.01 \\
\hline$A B$ date & 1.11 & $0.35-3.51$ & 0.85 \\
\hline \multicolumn{4}{|l|}{ Adjusted for } \\
\hline Nationality & 0.29 & $0.18-0.48$ & $<0.001$ \\
\hline Crowding & 1.30 & $0.83-2.04$ & 0.25 \\
\hline SES & 0.45 & $0.23-0.89$ & 0.02 \\
\hline
\end{tabular}

This fact also explains why H.p. prevalence was not significantly higher in children who had received antibiotic treatment more than six months before testing as compared with children who had been treated between six months and four weeks prior to testing (Table 2).

\section{DISCUSSION}

The results of this study showed that students who had been treated previously with antibiotics (regardless the reasons and type of antibiotic), had a significantly lower H.p. prevalence compared to those who had never taken antibiotics. H.p. prevalence increased with decreasing frequency of antibiotic treatments. This points out to the negative relationship between antibiotic treatment and the existence of H.p. infections in adolescence. Furthermore, the study shows that treatment frequency influenced $H$. pylori status much more than the particular date of treatment (Table 4).

In other words, not the specific time of the last antibiotic treatment but rather the absolute number of treatments in the past influences the prevalence of H.p. infection at a given time.
One limitation of this study is, however, that the presented results are based on retrospective questionnaire information. Clinical experience tells us that among 8th graders there are probably far fewer students who have never been treated with antibiotics than $30 \%$ we reported in this study. Nevertheless, the frequency of antibiotic treatment we found in 8th grade students (69\%) was significantly higher compared with data available from other studies of similar cohorts which ranges between 38\% (17) and a maximum of $56 \%$ (18). It can be assumed that some treatments may have occurred quite some time ago and were no longer remembered. Another explanation may be that some parents may not have been aware of a medication being actually an antibiotic.

Our results are supported by several other studies. For instance, one German study investigating 945 children (aged 5-8 years), found a significantly lower $H$.p. prevalence among children who had been previously treated with antibiotics in comparison to those who had never taken any. The type and reason for antibiotic treatment was not elucidated (5). Another example was shown in a 2001 study of 142 children (aged 1 to 12 years) in the city of Riga (Latvia): The authors reported a lower H.p. prevalence among 1 to 6 year old children who had been administered antibiotics during the preceding year in comparison to those who had been treated not that recently, more than a year ago or not at all (6). A longitudinal study carried out in Turkey among 327 children aged from 3 to 12 years reported a significantly lower H.p. prevalence among children who had been treated with antibiotics within 6 months prior to the study (19).

An U.S. study published in 2009 investigated factors which might affect the persistence of "chronic" H.p. infection (20). The study participants, from 6 to 84 months old, had undergone ${ }^{13} \mathrm{C}$-urea breath tests for H.p. at 6-months intervals. These data indicate as well that non-H.p. specific treatment with antibiotics affected H.p. prevalence negatively. However, this did not explain all cases of eradications. No information was presented about the medications administered. The authors concluded that H.p. infection in childhood does not necessarily have to be persistent as assumed so far.

Other studies reported on the effects of particular classes of antibiotics, for example a study conducted in 2002 in Ulm, Southern Germany, where 180 asymptomatic children (aged 1 to 4 years) of Turkish descent were investigated to gain information on the dynamics of H.p. infections in early childhood (21). The 
children were tested twice during an interval of several months using a stool antigen-test for H.p. infection. In association with spontaneous eradications, a slight effect could be detected with penicillin and macrolide therapy. These results were found only in the younger, 1-2 year old age group. The authors concluded that the world-wide decreasing H.p. prevalence was possibly associated with the increasing consumption of these two classes of antibiotics, especially the life-long effect of eradication during infancy. Our previously published results are concordant with these findings (22). A non significant increase of the H.p. prevalence between age 6 and 14 in our study population may be attributable to non-H.p. specific antibiotic therapy.

A study conducted in Sweden in 2005, investigating 146 children aged 6 months to 5 years, showed significantly lower H.p. prevalences in the previously antibiotic-treated children as compared to the untreated ones. The authors tried to elucidate the effects of the different classes of antibiotic substances. They assessed 65 cases which had been treated with an antibiotic monotherapy and found no significant difference in H.p. positivity in relation to the type of antibiotic (penicillin, ampicillin, amoxicillin, cotrimoxazol, cephalosporin, and erythromycin) (7).

In the previous studies, namely the LISS parts I and II of 1998 and 2000, 2,235 children were tested for H.p. at the time of school entry and second grade using the same ${ }^{13} \mathrm{C}$-urea breath test (23). Comparing the H.p. infection status for these 2 points in time, 4 cases of pathogen elimination were observed, most likely due to an antibiotic monotherapy (metronidazol, cephalosporin and 2x clarithromycin).

Nevertheless, the results remain conflicting. There are studies which show that previous treatment with antibiotics did not affect H.p. prevalence. In a 1997 questionnaire survey held among 475 adults, no association was found between H.p. prevalence and the antibiotic treatment administered within previous 5 years (24). Similarly, an investigation in Sweden, in which 305 children aged 5 months to 11 years were repeatedly tested serologically for H.p., showed no association between H.p. prevalence and antibiotic use at any time (25).

Several studies with adults did not show clear relationships between the presence of H.p. and the effect of antibiotic use for other reasons (26-28).

We have found that the influence of non-H.p. specific antibiotic treatment on the prevalence of H.p. infection is still debated contradictorily in the literature. Nevertheless, the number of publications which report on significant associations between non-H.p. specific antibiotic treatment and a decrease in H.p. prevalence, especially in childhood and adolescence far outweigh the contradicting reports. In the presented study conducted on a large population, the negative effect of non-H.p. specific antibiotic treatments on H.p . prevalence is further substantiated. It demonstrates the underestimation of the epidemiologic importance of antibiotic treatment of bacterial infections other than H.p. Perhaps even the course content on chronic H.p. infection needs to be revised in the future. For now, however, it might be advisable to include a question of previously prescribed and administered antibiotics as a confounding variable in any future epidemiological study. However, any assumptions on the biological effectiveness of the various types of antibiotics against H.p. cannot be made on the basis of these data, it would require further investigations.

\section{Acknowledgement}

We are grateful to all participating doctors and technical staff of the Public Health Services, Division of Children and Adolescents, City and County of Leipzig, for incorporating our study into their work schedule and the medical students for carrying out the tests.

We especially thank all children and their parents for their interest and participation in the study. Furthermore, we thank all members of the LISS study group for their excellent work.

Parts of the study were supported by the BMBF Federal Ministry of Education and Research (Germany), UFZ (Grant No. UFZ-20/97), and the State Ministry of Family and Health Saxony (Grant No. WVSMS/2001).

\section{Conflict of Interests}

None declared

\section{Ethical Approval}

The study was approved by the Ethics Committee of the University of Leipzig.

\section{REFERENCES}

1. Fischbach W, Malfertheiner P, Hoffmann JC, Bolten W, Bornschein J, Götze O, et al. S3-guideline "Helicobacter pylori and gastroduodenal ulcer disease". Z Gastroenterol. 2009 Jan;47(1):68-102. (In German.)

2. Stettin D, Waldmann A, Wolters M, Trunz B, Schauder P, Hahn A. Infection with Helicobacter pylori - outcome of a cross-sectional investigation. Dtsch Med Wochenschr. 2007 Dec;132(50):2677-82. (In German.)

3. Vale FF, Vítor JM. Transmission pathway of Helicobacter pylori: does food play a role in rural and urban areas? Int J Food Microbiol. 2010 Mar 31;138(1-2):1-12.

4. Daugule I, Rowland M. Helicobacter pylori infection in children. Helicobacter. 2008 Oct;13 Suppl 1:41-6.

5. Rothenbacher D, Bode G, Adler G, Brenner H. History of antibiotic treatment and prevalence of $\mathrm{H}$. pylori infection among children: results of a population-based study. J Clin Epidemiol. 1998 Mar;51(3):267-71.

6. Daugule I, Rumba I, Lindkvist P, Bergström M, Ejderhamn J. A relatively low prevalence of Helicobacter pylori infection in a healthy paediatric population in Riga, Latvia: a cross-sectional study. Acta Paediatr. 2001 Oct;90(10):1199-201.

7. Daugule I, Rumba I, Ejderhamn J. Previous antibacterial treatment due to concomitant infections in preschool children is associated with a lower Helicobacter pylori positivity. Scand J Infect Dis. 2005;37(5):326-9.

8. Malaty HM. Helicobacter pylori infection and eradication in paediatric patients. Paediatr Drugs. 2000 Sep-Oct;2(5):357-65.

9. Ahmed KS, Khan AA, Ahmed I, Tiwari SK, Habeeb MA, Ali SM, et al. Prevalence study to elucidate the transmission pathways of Helicobacter pylori at oral and gastroduodenal sites of a South Indian population. Singapore Med J. 2006 Apr;47(4):291-6.

10. Kivi M, Tindberg Y. Helicobacter pylori occurrence and transmission: a family affair? Scand J Infect Dis. 2006;38(6-7):407-17.

11. Czinn SJ. Helicobacter pylori infection: detection, investigation, and management. J Pediatr. 2005 Mar;146(3 Suppl):S21-6.

12. Lehours P, Yilmaz O. Epidemiology of Helicobacter pylori infection. Helicobacter. 2007 Oct;12 Suppl 1:1-3.

13. Krumbiegel P, Herbarth O, Fritz G, Schlink U, Gutsmuths FJ, Kindler A, et al. Helicobacter pylori prevalence in Leipzig's 1998 school entries: methodology and first results. Int J Hyg Environ Health. 2000 Mar;203(1):11-6.

14. Herbarth O, Krumbiegel P, Fritz GJ, Richter M, Schlink U, Müller DM, et al. Helicobacter pylori prevalences and risk factors among school beginners in a German urban center and its rural county. Environ Health Perspect. 2001 Jun;109(6):573-7.

15. Koletzko S. Gastritis and peptic ulcer. In: Rodeck B, Zimmer K, editors. Pediatric gastroenterology, hepatology, and nutrition. Heidelberg: Springer; 2008.

16. Chen CM, Mielck A, Fahlbusch B, Bischof W, Herbarth O, Borte M, et al. Social factors, allergen, endotoxin, and dust mass in mattress. Indoor Air. 2007 Oct;17(5):384-93. 
17. Abbas S, Ihle P, Heymans L, Küpper-Nybelen J, Schubert I. Differences in antibiotic prescribing between general practitioners and pediatricians in Hesse, Germany. Dtsch Med Wochenschr. 2010 Sep;135(37):1792-7. (In German.)

18. Schindler C, Krappweis J, Morgenstern I, Kirch W. Prescriptions of systemic antibiotics for children in Germany aged between 0 and 6 years. Pharmacoepidemiol Drug Saf. 2003 Mar;12(2):113-20.

19. Ozen A, Ertem D, Pehlivanoglu E. Natural history and symptomatology of Helicobacter pylori in childhood and factors determining the epidemiology of infection. J Pediatr Gastroenterol Nutr. 2006 Apr;42(4):398-404.

20. Broussard CS, Goodman KJ, Phillips CV, Smith MA, Fischbach LA, Day $\mathrm{RS}$, et al. Antibiotics taken for other illnesses and spontaneous clearance of Helicobacter pylori infection in children. Pharmacoepidemiol Drug Saf. 2009 Aug;18(8):722-9.

21. Rothenbacher D, Bode G, Brenner H. Dynamics of Helicobacter pylori infection in early childhood in a high-risk group living in Germany: loss of infection higher than acquisition. Aliment Pharmacol Ther. 2002 Sep;16(9):1663-8.

22. Bauer S, Krumbiegel P, Richter M, Richter T, Röder S, Rolle-Kampczyk $\mathrm{U}$, et al. Influence of sociodemographic factors on Helicobacter pylori prevalence variability among schoolchildren in Leipzig, Germany. A longterm follow-up study. Cent Eur J Public Health. 2011 Mar;19(1):42-5.
23. Rehmann A, Müller D, Krumbiegel P, Herbarth O, Handrick W, Borte M, et al. Spontaneous elimination of helicobacter pylori infection in children. Klin Padiatr. 2005 Jan-Feb;217(1):15-7. (In German.)

24. Rothenbacher D, Bode G, Adler G, Brenner H. Use of commonly prescribed antibiotics is not associated with prevalence of Helicobacter pylori infection in adults. Scand J Gastroenterol. 1997 Nov;32(11):1096-9.

25. Tindberg Y, Blennow M, Granström M. Clinical symptoms and social factors in a cohort of children spontaneously clearing Helicobacter pylori infection. Acta Paediatr. 1999 Jun;88(6):631-5.

26. Leung WK, Hung LCT, Kwok CKL, Leong RWL, Ng DKK, Sung JJY. Follow up of serial urea breath test results in patients after consumption of antibiotics for non-gastric infections. World J Gastroenterol. 2002 Aug;8(4):703-6.

27. Parsonnet J, Blaser MJ, Perez-Perez GI, Hargrett-Bean N, Tauxe RV. Symptoms and risk factors of Helicobacter pylori infection in a cohort of epidemiologists. Gastroenterology. 1992 Jan;102(1):41-6.

28. Akre K, Signorello LB, Engstrand L, Bergström R, Larsson S, Eriksson $\mathrm{BI}$, et al. Risk for gastric cancer after antibiotic prophylaxis in patients undergoing hip replacement. Cancer Res. 2000 Nov 15;60(22):6376-80.

Received March 7, 2013

Accepted in revised form November 8, 2013 